\title{
The dimensions of the sphenoid sinuses: evaluation before the functional endoscopic sinus surgery
}

\author{
J. Jaworek-Troć1, 2, M. Zarzecki ${ }^{1}$, I. Zamojska1 ${ }^{1}$, J. Iwanaga ${ }^{3}$, W. Przybycień ${ }^{1}$, M. Mazur ${ }^{1}$, \\ R. Chrzan², J.A. Walocha'10 \\ ${ }^{1}$ Department of Anatomy, Jagiellonian University Medical College, Krakow, Poland \\ ${ }^{2}$ Department of Radiology, Jagiellonian University Medical College, Krakow, Poland \\ ${ }^{3}$ Department of Neurosurgery, Tulane University, New Orleans, United States
}

[Received: 4 March 2020; Accepted: 18 May 2020]

Background: The following study aimed to evaluate the dimensions (anteroposterior, transverse and vertical) of the sphenoid sinuses in the adult population. Materials and methods: The study was conducted as a retrospective analysis of the computed tomography (CT) scans of the paranasal sinuses of 296 patients (147 females and 149 males), who did not present any pathology in the sphenoid sinuses. The CT scans of the paranasal sinuses were done with the spiral CT scanner, without using any contrast medium. After obtaining transverse planes, frontal and sagittal planes were created using secondary reconstruction tool.

Results: The anteroposterior dimension was found to be $2.65 \mathrm{~cm}$ on average, in the range of $0.5-4.3 \mathrm{~cm}$. The transverse dimension was on average $1.98 \mathrm{~cm}$, ranging from $0.5 \mathrm{~cm}$ to $4.9 \mathrm{~cm}$. The average vertical dimension was found to be $2.1 \mathrm{~cm}$, in the range of $0.7-3.7 \mathrm{~cm}$.

Conclusions: Due to the high incidence of the anatomical variants of the paranasal sinuses, a CT scan is recommended in all patients before a planned surgery in order to avoid the potential iatrogenic complications. Dimensions of the sphenoid sinuses might point towards more at risk variants, but there is still a substantial amount of research that needs to be done in that aspect. (Folia Morphol 2021; 80, 2: 275-282)

Key words: sphenoid sinus, anatomy, dimensions, functional endoscopic sinus surgery

\section{INTRODUCTION}

Sphenoid sinuses are located in the diaphysis of the sphenoid bone. They are air-filled spaces that are lined up with mucous membrane. There is a high incidence of variance in their size, shape, the number of the septa present and the extent of their filling with air $[9,10,12]$.

A surgeon, before carrying out an invasive procedure in the paranasal sinuses, has to take into account the adjoining structures (nervous and vascular) that are next to the walls of the sphenoid sinuses. It is crucial to evaluate the anatomical parameters of the sinuses ahead of the planned surgery (including endoscopy), as to minimise the surgical risk and avoid complications that might arise during the procedure $[1,6,8,11,13,14,17-20,22]$.

Address for correspondence: Prof. J.A. Walocha, MD, PhD, Department of Anatomy, Jagiellonian University Medical College, ul. Kopernika 12, 31-034 Kraków, Poland, tel: +48 1242295 11, e-mail: j.walocha@uj.edu.pl

This article is available in open access under Creative Common Attribution-Non-Commercial-No Derivatives 4.0 International (CC BY-NC-ND 4.0) license, allowing to download articles and share them with others as long as they credit the authors and the publisher, but without permission to change them in any way or use them commercially. 
A clear-cut image of the osseous structures of the paranasal sinuses can be obtained by the computed tomography (CT), which is regarded as one of the most accurate methods of imaging of the sinuses (it allows for a distinction between the anatomical variants of the sinuses).

Recently it has been possible to notice the advancement of the functional endoscopic sinus surgery (FESS) $[3,4]$. The minor number of the classical extensive surgeries of the paranasal sinuses still carried out was obtained thanks to the minimally invasive endoscopic procedures.

In the surgical treatment of the chronic paranasal sinusitis, the FESS is commonly regarded as a method of choice. In comparison to classical surgeries, endoscopic techniques allow for a better insight into the otherwise difficult to assess places, cause less collateral damage during the operation and facilitate a shorter recovery period for the patients $[6,15]$.

\section{MATERIALS AND METHODS}

Two hundred ninety-six patients ( $\mathrm{n}=296$; $147 \mathrm{fe}$ males, 149 males) were referred to the Department of Medical Imaging of the University Hospital in Krakow, Poland. People over 18 years of age, without any visible/confirmed pathology in the sphenoid sinuses, were included in this retrospective analysis of the paranasal sinuses $\mathrm{CT}$ scans. The patients who suffered from a head injury or underwent a surgical procedure involving nasal, orbital, or cranial basis regions were excluded from the study.

Standard procedure in the option Siemens CARE Dose 4D applied while obtaining the CT scans of the paranasal sinuses, using spiral CT scanner (Siemens Somatom Sensation 16). No contrast medium was given to the patients. Sagittal and frontal planes were obtained by using the multiplanar reconstruction (MPR) tool, after the images of transverse planes were taken. Siemens Volume Wizard diagnostic station was used in order to evaluate the data.

The analysis of the obtained images involved the three dimensions of each of the sphenoid sinuses studied: anteroposterior (in the longest part of the sinuses), transverse (in the widest part of the sinuses) and vertical dimensions (in the highest part of the sinuses).

\section{RESULTS}

The anteroposterior dimension was on average $2.65 \mathrm{~cm}(2.6 \mathrm{~cm}$ in females, $2.7 \mathrm{~cm}$ in males), in the range of $0.5-4.3 \mathrm{~cm}(0.5-4.2 \mathrm{~cm}$ in females, $0.6-4.3 \mathrm{~cm}$ in males). The smallest anteroposterior dimension of the right sphenoid sinuses noted was $0.6 \mathrm{~cm}$ $(1 \mathrm{~cm}$ in females, $0.6 \mathrm{~cm}$ in males), and $0.5 \mathrm{~cm}$ of the left sphenoid sinuses $(0.5 \mathrm{~cm}$ in females, $0.8 \mathrm{~cm}$ in males). On the other side, the biggest anteroposterior dimension of the right sphenoid sinuses was $4.1 \mathrm{~cm}$ ( $4 \mathrm{~cm}$ in females, $4.1 \mathrm{~cm}$ in males), and $4.3 \mathrm{~cm}$ of the left sphenoid sinuses ( $4.2 \mathrm{~cm}$ in females, 4.3 in males).

The median value of the anteroposterior dimension of the female sphenoid sinuses $(2.55 \mathrm{~cm} ; 2.25$ $-2.9 \mathrm{~cm}$ ) was significantly different from the median value of the same dimension in the males $(2.8 \mathrm{~cm}$; 2.4-3.1 cm; $p=0.001$, Mann-Whitney's test). Moreover, there was a significant variation found between the median value of the anteroposterior dimension of the right sphenoid sinuses in females $(2.7 \mathrm{~cm} ; 2.05-3.0 \mathrm{~cm})$ and males $(2.8 \mathrm{~cm} ; 2.2-3.2 \mathrm{~cm}$; $\mathrm{p}=0.021$, Mann-Whitney's test). Similarly, the median value of the anteroposterior dimension of the left sphenoid sinuses in females $(2.7 \mathrm{~cm} ; 2.1-3.0 \mathrm{~cm})$ was significantly different to the one in males $(2.9 \mathrm{~cm}$; 2.3-3.4 cm; $p=0.005$, Manna-Whitney's test).

Rarely there were sphenoid sinuses found that would have the same anteroposterior dimension they were noted only in 17 patients ( 12 females, 5 males).

No statistically significant differences were found between the prevalence of the different/equal anteroposterior dimension of the right and left sphenoid sinuses in females and males ( $p=0.075, \chi^{2}$ test). In both males and females the different dimension of the right and left sphenoid sinuses comprised over $90 \%$ of the cases (Tables 1, 2, Fig. 1).

The transverse dimension was $1.98 \mathrm{~cm}$ on average $(1.85 \mathrm{~cm}$ in females, $2.1 \mathrm{~cm}$ in males), in the range of $0.5-4.9 \mathrm{~cm}(0.7-3.7 \mathrm{~cm}$ in females, $0.5-4.9 \mathrm{~cm}$ in males). The smallest transverse dimension of the right sphenoid sinuses was $0.5 \mathrm{~cm}(0.7 \mathrm{~cm}$ in females, $0.5 \mathrm{~cm}$ in males), and $0.8 \mathrm{~cm}$ in the case of the left sinuses $(0.9 \mathrm{~cm}$ in females, $0.8 \mathrm{~cm}$ in males). On the other side, the biggest transverse dimension of the right sphenoid sinuses was $4.9 \mathrm{~cm}(3.2 \mathrm{~cm}$ in females, $4.9 \mathrm{~cm}$ in males), and $4.6 \mathrm{~cm}$ of the left sinuses (3.7 $\mathrm{cm}$ in females, $4.6 \mathrm{~cm}$ in males).

The median value of the transverse dimension of the female sphenoid sinuses $(1.75 \mathrm{~cm} ; 1.6-2 \mathrm{~cm})$ was significantly different to the one of males $(2 \mathrm{~cm} ; 1.75-2.4 \mathrm{~cm} ; \mathrm{p}=0.001$, Mann-Whitney's test). Moreover, there was a significant variation between 
Table 1. The anteroposterior dimensions of the sphenoid sinuses in centimetre

\begin{tabular}{lccc}
\hline The anteroposterior dimension & Females & Males & Total \\
\hline Overall & & & $2.65 \pm 0.54$ \\
Mean \pm standard deviation & $2.6 \pm 0.52$ & $2.75 \pm 0.54$ & $2.7(2.35-3)$ \\
Median $\left(0_{1}-0_{3}\right)$ & $2.55(2.25-2.9)$ & $2.8(2.4-3.1)$ & $0.5-4.3$ \\
Minimum-maximum & $0.5-4.3$ & $0.6-4.3$ & $2.63 \pm 0.69$ \\
Right sphenoid sinus & & & $2.7(2.175-3.2)$ \\
Mean \pm standard deviation & $2.56 \pm 0.65$ & $2.71 \pm 0.72$ & $0.6-4.1$ \\
Median $\left(0_{1}-0_{3}\right)$ & $2.7(2.05-3.0)$ & $2.8(2.2-3.2)$ & $2.67 \pm 0.76$ \\
Minimum-maximum & $1-4$ & $0.6-4.1$ & $2.8(2.2-3.2)$ \\
Left sphenoid sinus & & & $0.5-4.3$ \\
Mean \pm standard deviation & $2.55 \pm 0.72$ & $2.79 \pm 0.78$ & $2.9(2.3-3.4)$ \\
Median $\left(0_{1}-0_{3}\right)$ & $2.7(2.1-3.0)$ & $0.8-4.3$ & \\
Minimum-maximum & $0.5-4.3$ & & \\
\hline
\end{tabular}

Table 2. The prevalence of the different/equal anteroposterior (AP) dimensions of the right and left sphenoid sinuses

\begin{tabular}{lcccccc}
\hline & $\mathbf{F}$ & $\mathbf{F} \%$ & $\mathbf{M}$ & $\mathbf{M} \%$ & $\mathbf{F}+\mathbf{M}$ & $\mathbf{F}+\mathbf{M} \%$ \\
\hline APRSS $\neq$ LSS & 135 & $91.84 \%$ & 144 & $96.64 \%$ & 279 & $94.26 \%$ \\
APRSS=LSS & 12 & $8.16 \%$ & 5 & $3.36 \%$ & 17 & $5.74 \%$ \\
\hline
\end{tabular}

RSS — right sphenoid sinus; LSS — left sphenoid sinus; RSS $\neq$ LSS — different anteroposterior dimensions; RSS=LSS — equal anteroposterior dimensions; $F$ - females, F\% — the percentage of females, $\mathrm{M}$ - males; $\mathrm{M} \%$ - the percentage of males

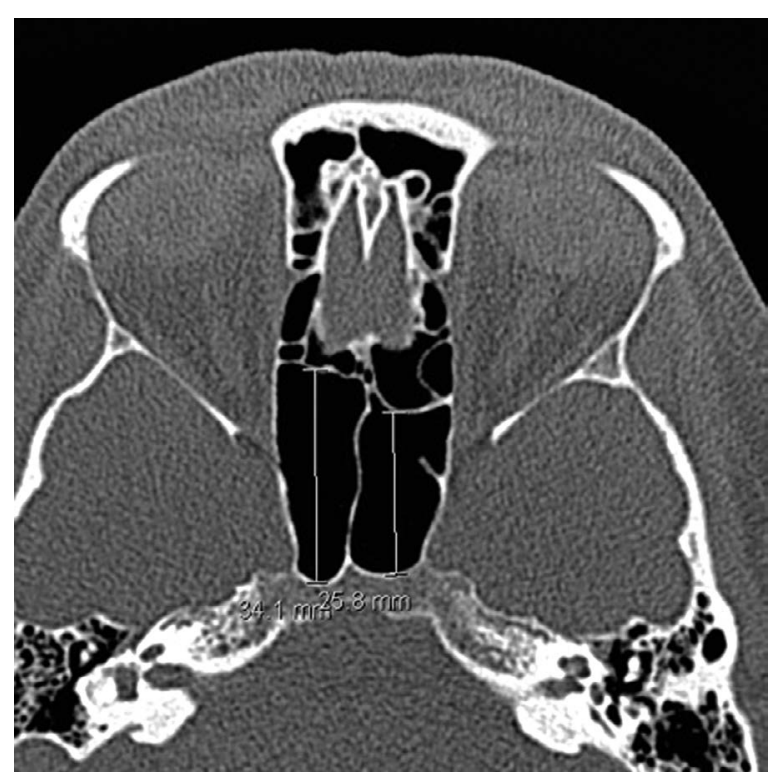

Figure 1. A computed tomography scan of the paranasal sinuses, transverse plane. The measurement method of the anteroposterior dimensions of the right and left sphenoid sinuses.

the median value of the transverse dimension of the right sphenoid sinuses in females $(1.8 \mathrm{~cm} ; 1.5-2.1 \mathrm{~cm})$ and males $(1.9 \mathrm{~cm} ; 1.5-2.4 \mathrm{~cm} ; \mathrm{p}=0.031$, Mann-Whit- ney's test). Similarly, the median value of the transverse dimension of the left sphenoid sinuses in females $(1.7 \mathrm{~cm} ; 1.5-2.3 \mathrm{~cm})$ differed significantly from the one in males $(2.1 \mathrm{~cm} ; 1.7-2.7 \mathrm{~cm} ; \mathrm{p}<0.001$, Mann-Whitney's test).

Likewise in the case of this dimension there were not many sinuses with equal transverse dimensions found - such situation was noted only in 14 patients (7 females, 7 males).

No statistically significant relations were found between the prevalence of the different/equal transverse dimensions of the right and left sphenoid sinuses in females and males ( $p=0.979, \chi^{2}$ test). In both female and male groups, the sinuses that had different transverse dimensions of the right and left sphenoid sinuses predominated (95\%; Tables 3, 4, Fig. 2).

The vertical dimension was $2.1 \mathrm{~cm}$ on average ( $2 \mathrm{~cm}$ in females, $2.2 \mathrm{~cm}$ in males), in the range of $0.7-3.7 \mathrm{~cm}(0.7-3.7 \mathrm{~cm}$ in females, $1-3.4 \mathrm{~cm}$ in males). The smallest vertical dimension of the right sphenoid sinuses was $1 \mathrm{~cm}(1.1 \mathrm{~cm}$ in females, $1 \mathrm{~cm}$ in males), and $0.7 \mathrm{~cm}$ of the left sphenoid sinuses $(0.7 \mathrm{~cm}$ in females, $1.1 \mathrm{~cm}$ in males), and the biggest vertical dimension of the right sphenoid sinuses was $3.7 \mathrm{~cm}$ 
Table 3. The transverse dimensions of the sphenoid sinuses in centimetre

\begin{tabular}{lccc}
\hline The transverse dimension & Females & Males & Total \\
\hline Overall & & & $1.98 \pm 0.49$ \\
Mean \pm standard deviation & $1.85 \pm 0.38$ & $2.12 \pm 0.54$ & $1.85(1.65-2.15)$ \\
Median $\left(0_{1}-0_{3}\right)$ & $1.75(1.6-2)$ & $2(1.75-2.4)$ & $0.5-4.9$ \\
Minimum-maximum & $0.7-3.7$ & $0.5-4.1$ & $1.93 \pm 0.64$ \\
Right sphenoid sinus & & & $1.8(1.5-2.2)$ \\
Mean \pm standard deviation & $1.82 \pm 0.48$ & $2.04 \pm 0.76$ & $0.5-4.9$ \\
Median $\left(0_{1}-0_{3}\right)$ & $1.8(1.5-2.1)$ & $1.9(1.5-2.4)$ & $2.05 \pm 0.70$ \\
Minimum-maximum & $0.7-3.2$ & $0.5-4.9$ & $1.9(1.5-2.5)$ \\
Left sphenoid sinus & & & $0.8-4.6$ \\
Mean \pm standard deviation & $1.88 \pm 0.60$ & $2.21 \pm 0.75$ & $2.1(1.7-2.7)$ \\
Median $\left(0_{1}-0_{3}\right)$ & $1.7(1.5-2.3)$ & $0.8-4.6$ & \\
Minimum-maximum & $0.9-3.7$ & & \\
\hline
\end{tabular}

Table 4. The prevalence of the different/equal transverse dimensions (Transv.) of the right and left sphenoid sinuses

\begin{tabular}{lcccccc}
\hline & $\mathbf{F}$ & $\mathbf{F} \%$ & $\mathbf{M}$ & $\mathbf{M} \%$ & $\mathbf{F}+\mathbf{M}$ & $\mathbf{F}+\mathbf{M} \%$ \\
\hline Transv. RSS $\neq$ LSS & 140 & $95.24 \%$ & 142 & $95.3 \%$ & 282 & $95.27 \%$ \\
Transv. RSS=LSS & 7 & $4.76 \%$ & 7 & $4.7 \%$ & 14 & $4.73 \%$ \\
\hline
\end{tabular}

RSS — right sphenoid sinus; LSS — left sphenoid sinus; RSS $\neq L S S$ - different transverse dimensions; $R S S=L S S$ - equal transverse dimensions; $F$ - females; $F \%$ - the percentage of females; $M$ - males; $M \%$ - the percentage of males

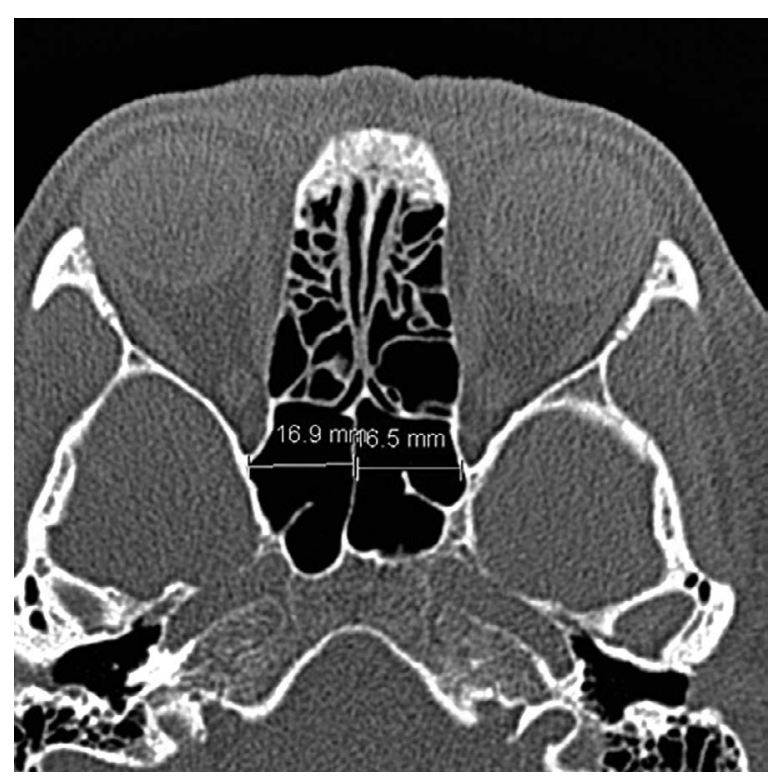

Figure 2. A computed tomography scan of the paranasal sinuses, transverse plane. The measurement method of the transverse dimensions of the right and left sphenoid sinuses.

(3.7 cm in females, $3.4 \mathrm{~cm}$ in males), and $3.2 \mathrm{~cm}$ of the left sphenoid sinuses $(3.1 \mathrm{~cm}$ in females, $3.2 \mathrm{~cm}$ in males).
The median value of the vertical dimension of the female sphenoid sinuses $(2 \mathrm{~cm} ; 1.85-2.2 \mathrm{~cm}$ ) was significantly different from the ones of males (2.2 cm; 1.95-2.45 cm; p $=0.001$, Mann-Whitney's test). Moreover, there was a significant difference between the median values of the vertical dimension of the right sphenoid sinuses in females $(2.1 \mathrm{~cm} ; 1.8-2.3 \mathrm{~cm})$ and males $(2.2 \mathrm{~cm} ; 1.9-2.5 \mathrm{~cm}$; $\mathrm{p}=0.002$, Mann-Whitney's test). Similarly, the median value of the vertical dimension of the left sphenoid sinuses in females $(2 \mathrm{~cm} ; 1.7-2.25 \mathrm{~cm})$ differed significantly from the one of males $(2.2 \mathrm{~cm} ; 1.9-2.5 \mathrm{~cm}$; $p<0.001$, Mann-Whitney's test).

Likewise in the case of this dimension, there were not many sinuses with equal vertical dimensions such situation was noted only in 24 patients (12 females, 12 males).

No statistically significant relations were found between the prevalence of the different/equal vertical dimensions of the right and left sphenoid sinuses in females and males ( $p=0.972, \chi^{2}$ test). In both female and male groups the sphenoid sinuses with varied vertical dimensions predominated (92\%; Tables 5, 6, Fig. 3). 
Table 5. The vertical dimensions of the sphenoid sinuses in centimetre

\begin{tabular}{lccc}
\hline The vertical dimension & Females & Males & Total \\
\hline Overall & & & $2.12 \pm 0.35$ \\
Mean \pm standard deviation & $2.02 \pm 0.31$ & $2.21 \pm 0.31$ & $2.1(1.9-2.3)$ \\
Median $\left(0_{1}-0_{3}\right)$ & $2(1.85-2.2)$ & $2.2(1.95-2.45)$ & $0.7-3.7$ \\
Minimum-maximum & $0.7-3.7$ & $1.0-3.4$ & $2.125 \pm 0.44$ \\
Right sphenoid sinus & & & $2.1(1.8-2.4)$ \\
Mean \pm standard deviation & $2.05 \pm 0.39$ & $2.2 \pm 0.49$ & $1-3.7$ \\
Median $\left(0_{1}-0_{3}\right)$ & $2.1(1.8-2.3)$ & $2.2(1.9-2.5)$ & $2.11 \pm 0.43$ \\
Minimum-maximum & $1.1-3.7$ & $1-3.4$ & $2.1(1.8-2.4)$ \\
Left sphenoid sinus & & & $0.7-3.2$ \\
Mean \pm standard deviation & $1.99 \pm 0.40$ & $2.23 \pm 0.42$ & $2.2(1.9-2.5)$ \\
Median $\left(0_{1}-0_{3}\right)$ & $2(1.7-2.25)$ & $1.1-3.2$ & \\
Minimum-maximum & $0.7-3.1$ & & \\
\hline
\end{tabular}

Table 6. The prevalence of the different/equal vertical dimensions (Vert.) of the right and left sphenoid sinuses

\begin{tabular}{lcccccc}
\hline & $\mathbf{F}$ & $\mathbf{F} \%$ & $\mathbf{M}$ & $\mathbf{M} \%$ & $\mathbf{F}+\mathbf{M}$ & $\mathbf{F}+\mathbf{M} \%$ \\
\hline Vert. RSS $\neq$ LSS & 135 & $91.84 \%$ & 137 & $91.95 \%$ & 272 & $91.89 \%$ \\
Vert. RSS $=$ LSS & 12 & $8.16 \%$ & 12 & $8.05 \%$ & 24 & $8.11 \%$ \\
\hline
\end{tabular}

RSS — right sphenoid sinus; LSS — left sphenoid sinus; RSS $\neq$ LSS — different vertical dimensions; RSS=LSS — equal vertical dimensions; $F$ - females; F\% — the percentage of females; $M$ - males; $M \%$ - the percentage of males

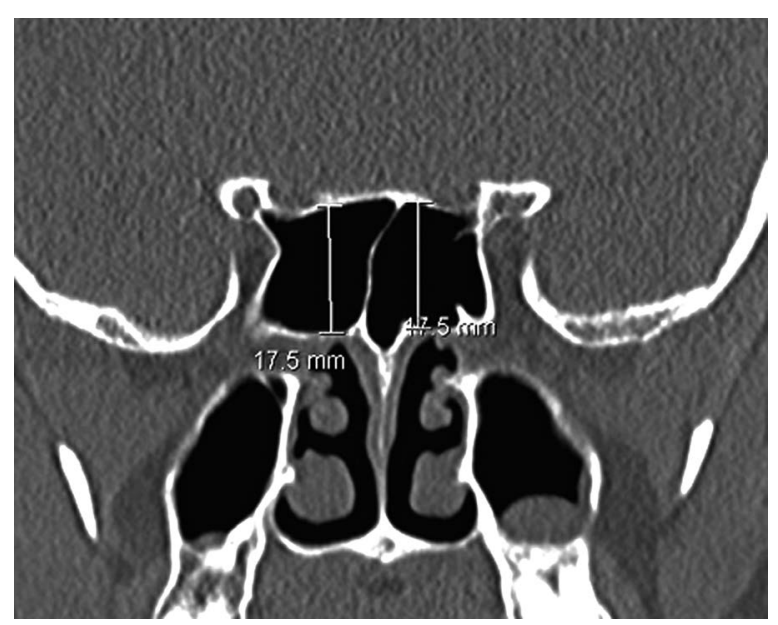

Figure 3. A computed tomography scan of the paranasal sinuses, frontal plane. The measurement method of the vertical dimensions of the right and left sphenoid sinuses.

\section{DISCUSSION}

The average dimensions of the sphenoid sinuses did not differ significantly amongst the genders.

The anteroposterior dimension was $2.65 \mathrm{~cm}$ on average, in the range of $0.5-4.3 \mathrm{~cm}$. The different anteroposterior dimension of the two sphenoid sinuses in one patient was the most prevalent variant $-94.26 \%$ of the patients.

Similar results were obtained by Mutlu et al. [18], who found the anteroposterior dimension to be $2.76 \mathrm{~cm}$ on average (ranging from 1.07 to $4.17 \mathrm{~cm}$ ), and Sareen et al. [20], who determined it to be $2.5 \mathrm{~cm}$ on average (in the range of $1.3-3.4 \mathrm{~cm}$ ).

Elwany et al. [5] provided the following data for the anteroposterior dimension of the sphenoid sinuses: the mean of $1.6 \mathrm{~cm}$ (the presellar type) and $3.1 \mathrm{~cm}$ (the postsellar type), the smallest $1.2 \mathrm{~cm}$ (the presellar type) and $2.6 \mathrm{~cm}$ (the postsellar type), as well as the biggest $1.8 \mathrm{~cm}$ (the presellar type) and $3.9 \mathrm{~cm}$ (the postsellar type). On the other hand, Stokovic et al. [21] evaluated the average anteroposterior dimension to be $1.66 \mathrm{~cm}$ (in the range of $0.65-3.45 \mathrm{~cm}$ ) (Table 7).

The transverse dimension was $1.98 \mathrm{~cm}$ on average, in the range of $0.5-4.9 \mathrm{~cm}$. The different anteroposterior dimensions of the two sphenoid sinuses in one patient was the most prevalent variant $-95.27 \%$ of the patients $(95.24 \%$ of females, $95.3 \%$ of males). 
Table 7. The reported anteroposterior dimensions of the sphenoid sinuses $(\mathrm{cm})$

\begin{tabular}{|c|c|c|c|c|c|}
\hline Author (material and methods) & The mean & The smallest & The biggest & $\mathrm{RSS}=\mathrm{LSS}$ & $\mathrm{RSS} \neq \mathrm{LSS}$ \\
\hline Mutlu et al. (69 HRCT) & 2.76 & 1.07 & 4.17 & - & - \\
\hline Sareen et al. (20 skulls, dissection study) & 2.5 & 1.3 & 3.4 & - & - \\
\hline $\begin{array}{l}\text { Elwany et al. } 1983 \text { ( } 100 \text { X-rays, } 100 \text { skulls X-rayed, } \\
50 \text { skulls — dissection study) }\end{array}$ & $1.6 / 3.1$ & $1.2 / 2.6$ & $1.8 / 3.9$ & - & - \\
\hline Stokovic et al. (51 skulls CBCT) & 1.66 & 0.65 & 3.45 & - & - \\
\hline Jaworek-Troć et al. (296 CT scans) & 2.65 & 0.5 & 4.3 & $5.74 \%$ & $94.26 \%$ \\
\hline
\end{tabular}

CT — computed tomography; CBCT — cone-beam computed tomography; HRCT — high-resolution CT; RSS — right sphenoid sinus; LSS — left sphenoid sinus; RSS $\neq$ LSS — different anteroposterior dimensions; RSS=LSS — equal anteroposterior dimensions

Table 8. The reported transverse dimensions of the sphenoid sinuses $(\mathrm{cm})$

\begin{tabular}{|c|c|c|c|c|c|}
\hline Author (material and methods) & The mean & The smallest & The biggest & RSS $=$ LSS & $\mathrm{RSS} \neq \mathrm{LSS}$ \\
\hline Mutlu et al. (69 HRCT) & 3.18 & 2.13 & 5.54 & - & - \\
\hline $\begin{array}{l}\text { Elwany et al. } 1983 \text { (100 X-rays, } 100 \text { skulls X-rayed, } \\
50 \text { skulls — dissection study) }\end{array}$ & $1.2 / 1.9$ & $0.7 / 1.4$ & $1.4 / 2.4$ & - & - \\
\hline Stokovic et al. (51 skulls CBCT) & 1.43 & 0.55 & 3.5 & - & - \\
\hline Jaworek-Troć et al. (296 CT scans) & 1.98 & 0.5 & 4.9 & $4.73 \%$ & $95.27 \%$ \\
\hline
\end{tabular}

CT — computed tomography; CBCT — cone-beam computed tomography; HRCT — high-resolution CT; RSS — right sphenoid sinus; LSS — left sphenoid sinus; RSS $\neq$ LSS — different transverse dimensions; RSS $=$ LSS — equal transverse dimensions

Table 9. The reported vertical dimensions of the sphenoid sinuses $(\mathrm{cm})$

\begin{tabular}{|c|c|c|c|c|c|}
\hline Author (material and methods) & The mean & The smallest & The biggest & RSS $=$ LSS & RSS $\neq$ LSS \\
\hline Sareen et al. (20 skulls, dissection study) & 2.2 & 1.4 & 3.6 & & \\
\hline $\begin{array}{l}\text { Awadalla et al. ( } 25 \text { skulls, dissection study and } \\
364 \text { CT and/or MRI scans) }\end{array}$ & 1.89 & & & - & - \\
\hline $\begin{array}{l}\text { Elwany et al. } 1983 \text { (100 X-rays, } 100 \text { skulls X-rayed, } \\
50 \text { skulls - dissection study) }\end{array}$ & $1.4 / 2.6$ & $1.0 / 2.4$ & $1.6 / 2.9$ & - & - \\
\hline Stokovic et al. (51 skulls CBCT) & 1.71 & 0.96 & 3.25 & - & - \\
\hline Jaworek-Troć et al. (296 CT scans) & 2.1 & 0.7 & 3.7 & $8.11 \%$ & $91.89 \%$ \\
\hline
\end{tabular}

CT — computed tomography; CBCT — cone-beam computed tomography; HRCT — high-resolution CT; MRI — magnetic resonance imaging; RSS — right sphenoid sinus; LSS — left sphenoid sinus; RSS $\neq$ LSS - different vertical dimensions; RSS = LSS - equal vertical dimensions

Mutlu et al. [18] obtained similar results, evaluating the mean transverse dimension of the right and left sphenoid sinuses as $3.18 \mathrm{~cm}$ (in the range of $2.13-5.54 \mathrm{~cm}$ ). However, the aforementioned researchers provided the total dimension of the both sinuses (combining the measurement of the right and left sphenoid sinuses).

Elwany et al. [5] provided the following transverse dimensions of the sphenoid sinuses: the mean of $1.2 \mathrm{~cm}$ (the presellar type) and $1.9 \mathrm{~cm}$ (the postsellar type), the smallest $0.7 \mathrm{~cm}$ (the presellar type) and $1.4 \mathrm{~cm}$ (the postsellar type) and the biggest $1.4 \mathrm{~cm}$ (the presellar type) and $2.4 \mathrm{~cm}$ (the postsellar type). On the other hand, Stokovic et al. [21] estimated the average transverse dimension as $1.43 \mathrm{~cm}$ (ranging from 0.55 to $3.5 \mathrm{~cm}$ ) (Table 8).
The vertical dimension was $2.1 \mathrm{~cm}$ on average, in the range of $0.7-3.7 \mathrm{~cm}$. The different vertical dimensions in one patient was the most often variant - in $91.89 \%$ of the patients $(91.84 \%$ females, $91.95 \%$ males).

Similar results were obtained by Sareen et al. [20], who assessed the mean vertical dimension of the sphenoid sinuses to be $2.2 \mathrm{~cm}$ (ranging from 1.4 to $3.6 \mathrm{~cm}$ ).

Awadalla et al. [2] provided a different method of measuring the sphenoid sinuses by taking the length of the sinuses in their superior (the mean length was $13.9 \mathrm{~mm}$ ) and inferior parts (the mean length was $25.9 \mathrm{~mm}$ ), as well as the height in their anterior (the mean height was $18.9 \mathrm{~mm}$ ) and posterior parts (the mean height was $12.1 \mathrm{~mm}$ ). The mean height obtained by the aforementioned scientists in the 
anterior part of the sinuses is akin to the average vertical dimension obtained in the present study. The discrepancies may be due to the method of measuring the dimensions of the sphenoid sinuses.

Elwany et al. [5] reported the following data for the vertical dimensions of the sphenoid sinuses: the mean of $1.4 \mathrm{~cm}$ (the presellar type) and $2.6 \mathrm{~cm}$ (the postsellar type), the smallest $1.0 \mathrm{~cm}$ (the presellar type) and $2.4 \mathrm{~cm}$ (the postsellar type), as well as the biggest $1.6 \mathrm{~cm}$ (the presellar type) and $2.9 \mathrm{~cm}$ (the postsellar type). On the other hand, Stokovic et al. [21] evaluated the average vertical dimension of the sphenoid sinuses to be $1.71 \mathrm{~cm}$ (ranging from 0.96 to $2.5 \mathrm{~cm}$ ) (Table 9).

Lupascu et al. [16] evaluated the mean dimensions of the sphenoid sinuses as $24 / 20.5 /$ $/ 18 \mathrm{~mm}(23.4 / 22.1 / 19.2 \mathrm{~mm}$ for the male group and 24.5/18.6/17.1 $\mathrm{mm}$ for the female group), but they did not provide the methods or the information to which dimension the obtained data applies.

The size of the sphenoid sinuses can be a predictor of the thickness of its walls, as suggested by Elwany et al. [5] who noted an inverse correlation between them, i.e. the bigger the sinus, the thinner its walls. That fact is of immense importance, as there is a higher risk of iatrogenic injuries done to the neighbouring critical neurovascular structures, namely the carotid artery or the optic nerve, when the walls of the sphenoid sinus are thinner [5]. The aforementioned authors have also found that the intercarotid distance was 4-9 $\mathrm{mm}$ shorter than the transverse dimension of the sinus, possibly allowing to pinpoint the location of the carotid arteries without any carotid dehiscence visible within the lumen of the sinus during the surgery [5].

Furthermore, there are studies that have found a correlation between the presence of the protrusion of the carotid canal or the optic nerve into the lumen of the sphenoid sinus and its type or dimensions [7, 21]. Stokovic et al. [21] noticed that in the case of the sellar type of the sinuses, chance of it being of "high risk" (defined as "pneumatisation extensions to all parts of the sphenoid and protrusions of all neurovascular structures," i.e. the maxillary nerve, pterygoid nerve, optic nerve and internal carotid artery) increased with its dimensions. The aforementioned authors have divided it further into three subcategories: a) the first one with high probabilities of pterygoid process pneumatisation and optic and pterygoid nerve protru- sions increased with sinus' height; b) the second one with high probabilities of pterygoid process and greater wings pneumatisation and maxillary nerve protrusions associated with width; $c$ ) and the third one with contra- and ipsi-lateral internal carotid protrusion with higher odds in the postsellar type and with greater sinus' length [21]. Notwithstanding, the authors themselves state that more research should be carried out due to the limited sample they had (51 skulls).

\section{CONCLUSIONS}

As pointed by our analysis, the anteroposterior dimension was on average $2.65 \mathrm{~cm}$, the transverse dimension $1.98 \mathrm{~cm}$, and the vertical dimension $2.1 \mathrm{~cm}$. The great variance in the anatomy of the paranasal sinuses may complicate the surgical procedures undertaken in the aforementioned region. Knowledge of the dimensions of the sphenoid sinuses might point towards a higher chance of various neurovascular structures protrusion that might not be noted on standard imaging. Nonetheless, there is still a need of further research in this aspect that might hopefully prove useful in avoiding iatrogenic injuries to critical neurovascular structures surrounding the sphenoid sinuses. As such a study has not yet been conducted in the Polish population, we aimed to present the up-to-date representation of sphenoid sinuses' dimensions combined with deductions of other, referenced here authors, in furtherance of diminishing the number of iatrogenic complications in the meantime.

\section{REFERENCES}

1. Abdullah BJ, Arasaratnam A, Kumar G, et al. The sphenoid sinuses: computed tomographic assessment of septation, relationship to the internal carotid arteries and sidewall thickness in the Malaysian population. J HK Coll Radiol. 2001; 4: 185-188.

2. Awadalla AM, Hussein Y, ElKammash TH. Anatomical and radiological parameters of the sphenoidal sinus among Egyptians and its impact on sellar region surgery. Egyptian J Neurosurgery. 2015; 30(1): 1-12.

3. Becker DG. The minimally invasive, endoscopic approach to sinus surgery. J Long Term Eff Med Implants. 2003; 13(3): 207-221, doi: 10.1615/jlongtermeffmedimplants. v13.i3.70, indexed in Pubmed: 14516186.

4. Bogusławska R. Badanie zatok przynosowych metodą tomografii komputerowej dla celów chirurgii endoskopowej. Warszawa, 1995.

5. Elwany S, Yacout YM, Talaat M, et al. Surgical anatomy of the sphenoid sinus. J Laryngol Otol. 1983; 97(3): 227-241, doi: 10.1017/s0022215100094056, indexed in Pubmed: 6833847. 
6. Eryilmaz A, Ozeri C, Bayiz U, et al. Functional endoscopic sinus surgery (FESS). Turk J Med Res. 1993; 11(5): 221-223.

7. Güldner C, Pistorius SM, Diogo I, et al. Analysis of pneumatization and neurovascular structures of the sphenoid sinus using cone-beam tomography (CBT). Acta Radiol. 2012; 53(2): 214-219, doi: 10.1258/ar.2011.110381, indexed in Pubmed: 22383784.

8. Haetinger RG, Navarro JAC, Liberti EA. Basilar expansion of the human sphenoidal sinus: an integrated anatomical and computerized tomography study. Eur Radiol. 2006; 16(9): 2092-2099, doi: 10.1007/s00330-006-0208-3, indexed in Pubmed: 16642328.

9. Jaworek-Troć J, Zarzecki M, Bonczar A, et al. Sphenoid bone and its sinus - anatomo-clinical review of the literature including application to FESS. Folia Med Cracov. 2019; 59(2): 45-59, doi: 10.24425/fmc.2019.128453.

10. Jaworek-Troć J, Zarzecki M, Mróz l, et al. The total number of septa and antra in the sphenoid sinuses - evaluation before the FESS. Folia Med Cracov. 2018; 58(3): 67-81, doi: 10.24425/fmc.2018.125073, indexed in Pubmed: 30521512.

11. Kantarci M, Karasen RM, Alper F, et al. Remarkable anatomic variations in paranasal sinus region and their clinical importance. Eur J Radiol. 2004; 50(3): 296-302, doi: 10.1016/j.ejrad.2003.08.012, indexed in Pubmed: 15145491.

12. Kapakin S. The paranasal sinuses: three-dimensional reconstruction, photo-realistic imaging, and virtual endoscopy. Folia Morphol. 2016; 75(3): 326-333, doi: 10.5603/ FM.a2016.0006, indexed in Pubmed: 26916200.

13. Kazkayasi M, Karadeniz Y, Arikan OK. Anatomic variations of the sphenoid sinus on computed tomography. Rhinology. 2005; 43(2): 109-114, indexed in Pubmed: 16008065.
14. Keast A, Yelavich S, Dawes $P$, et al. Anatomical variations of the paranasal sinuses in Polynesian and New Zealand European computerized tomography scans. Otolaryngol Head Neck Surg. 2008; 139(2): 216-221, doi: 10.1016/j. otohns.2008.05.014, indexed in Pubmed: 18656718.

15. Krzeski A, Osuch-Wójcikiewicz E, Szwedowicz P, et al. Chirurgia endoskopowa $w$ leczeniu guzów jam nosa i zatok przynosowych. Mag ORL. 2004; 3(3): 79-84.

16. Lupascu M, Comsa G, Zainea V. Anatomical variations of the sphenoid sinus: a study of 200 cases. ARS Medica Tomitana. 2014; 20(2): 57-62, doi: 10.2478/arsm-2014-0011.

17. Mafee MF, Chow JM, Meyers R. Functional endoscopic sinus surgery: anatomy, CT screening, indications, and complications. Am J Roentgenol. 1993; 160(4): 735-744, doi: 10.2214/ajr.160.4.8456654, indexed in Pubmed: 8456654.

18. Mutlu C, Unlu HH, Goktan C, et al. Radiologic anatomy of the sphenoid sinus for intranasal surgery. Rhinology. 2001; 39(3): 128-132, indexed in Pubmed: 11721501.

19. Pérez-Piñas I, Sabaté J, Carmona A, et al. Anatomical variations in the human paranasal sinus region studied by CT. J Anat. 2000; 197 (Pt 2): 221-227, doi: 10.1046/j.14697580.2000.19720221.x, indexed in Pubmed: 11005714.

20. Sareen D, Agarwal AK, Kaul JM, et al. Study of sphenoid sinus anatomy in relation to endoscopic surgery. Int J Morphol. 2005; 23(3), doi: 10.4067/s071795022005000300012.

21. Štoković N, Trkulja V, Dumić-Čule I, et al. Sphenoid sinus types, dimensions and relationship with surrounding structures. Ann Anat. 2016; 203: 69-76, doi: 10.1016/j. aanat.2015.02.013, indexed in Pubmed: 25843780.

22. Terra ER, Guedes FR, Manzi FR, et al. Pneumatization of the sphenoid sinus. Dentomaxillofac Radiol. 2006; 35(1): 47-49, doi: 10.1259/dmfr/55048928, indexed in Pubmed: 16421265. 